\author{
Marquette University \\ e-Publications@Marquette
}

College of Nursing Faculty Research and

Publications

Nursing, College of

2007

\title{
The Bath Environment, the Bathing Task, and the Older Adult: A Review and Future Directions for Bathing Disability Research
}

Susan L. Murphy

University of Michigan

Kimberlee A. Gretebeck

Marquette University, kimberlee.gretebeck@marquette.edu

Neil B. Alexander

University Of Michigan

Follow this and additional works at: https://epublications.marquette.edu/nursing_fac

Part of the Nursing Commons

\section{Recommended Citation}

Murphy, Susan L.; Gretebeck, Kimberlee A.; and Alexander, Neil B., "The Bath Environment, the Bathing Task, and the Older Adult: A Review and Future Directions for Bathing Disability Research" (2007). College of Nursing Faculty Research and Publications. 852.

https://epublications.marquette.edu/nursing_fac/852 
Marquette University

e-Publications@Marquette

\section{Nursing Faculty Research and Publications/College of Nursing}

This paper is NOT THE PUBLISHED VERSION; but the author's final, peer-reviewed manuscript. The published version may be accessed by following the link in the citation below.

Disability and Rehabilitation, Vol. 29, No. 14 (2007): 1067-1075. DOI. This article is (C) Taylor \& Francis and permission has been granted for this version to appear in e-Publications@Marquette. Taylor \& Francis does not grant permission for this article to be further copied/distributed or hosted elsewhere without express permission from Taylor \& Francis.

\section{The Bath Environment, The Bathing Task, And the Older Adult: A Review and Future Directions for Bathing Disability Research}

\section{Susan L. Murphy}

Division of Geriatric Medicine, Department of Internal Medicine, University of Michigan, Ann Arbor, Michigan

Kimberlee A. Gretebeck

School of Nursing, University of Michigan, Ann Arbor, Michigan

Neil B. Alexander

Geriatric Research, Education and Clinical Center, Veterans Affairs Ann Arbor Health Care System, Michigan

\section{Abstract}

Purpose. To review existing research studies to identify optimal intervention strategies for remediation and prevention of bathing disability and future directions for bathing disability research. 
Method. Bathing disability, defined as problems in the interaction between the person and the environment during bathing performance, is examined through a comprehensive, narrative literature review.

Results. Most studies focus on the relationship between the person and the environment (such as assistive device use and environmental hazards) while fewer studies focus on analysis of the bathing task or the interaction of the person, environment, and bathing task. Of intervention studies, most do not focus solely on remediation of bathing disability and outcomes vary widely.

Conclusions. In order to help remediate and prevent bathing disability, it will be necessary to better understand and measure the person-environment-occupation interaction involved in bathing as it relates to specific groups of older adults.

\section{Introduction}

Approximately $5-7 \%$ of community-living older adults require personal assistance with bathing [1]. Bathing is one of the first activities of daily living in which people become disabled [2],[3], and bathing disability is associated with many adverse consequences such as increased hospital utilization [4], admission to skilled nursing facilities [5], incidence of bone fractures [6], and mortality [7]. Despite the consequences, little is known about how to best remediate bathing performance problems and prevent bathing disability. One reason for this lack of knowledge may be that bathing is a difficult task to research. It is complex, requiring many personal capacities, and it is closely related to environmental factors. The purpose of this paper is to (i) describe a theoretical model for conceptualizing bathing disability, (ii) summarize literature according to each part of the model, (iii) identify empirically-tested treatment strategies, and (iv) suggest future directions for bathing disability research.

\section{Bathing disability and the person-environment relationship}

It is increasingly recognized that the influence of the environment on health and functioning in older adults has not been well studied [8],[9]. A recent review of research on home environments concluded that the few studies carried out tend to be descriptive in nature and lack a clear theoretical base [10]. In order to help people function in their everyday lives, a better understanding of the relationship between a person and his or her environment is needed [10],[11].

Many general models of disability incorporate the environment, including the International Classification of Functioning, Disability, and Health [12], and the Disablement Process [9]. Within the field of occupational therapy, the person-environment-occupation (P-E-O) model [13] was developed to guide treatment for individual clients. This model is particularly useful to examine bathing disability research and identify gaps in the knowledge. In the model, three broadly-defined domains represent a holistic picture of task performance: The person (who has unique characteristics and capacities), the environment (which includes physical and social aspects that are dynamic over time) and the occupation (which involves all elements of the task and subtasks) [13]. The interaction among the person, environment, and occupation (called the P-E-O interaction) identifies problems in task performance. Bathing disability, therefore, can be defined as problems in the P-E-O interaction that impair bathing performance.

The P-E-O model is also a valuable tool to better understand and develop research on the prevention of bathing disability. The definition of the environment is particularly critical to use for assessment of future disability because environmental barriers may arise from changes in personal support as well as from reductions in personal capacity. In addition, the inclusion of the occupation domain helps to broaden the conceptualization of the bathing task to not only include sub-tasks, but also how the task is performed to meet individual needs, such as timing, routine, and frequency of task performance. 


\section{Bathing within the P-E-O model}

Several factors are specified in each domain of the model representing the P-E-O interaction involved in bathing (seeFigure 1). These factors include anything that could potentially help or hinder bathing performance. Within the person domain, there are physical factors (e.g., balance, gait, strength, endurance, pain, limited range of motion, decreased vision, impaired sensation), psychological factors (e.g., depression, low falls efficacy [i.e., lack of confidence in ability to perform activities without falling]), attitudes and preferences about bathing, and cognition. The environmental domain includes the physical and social environment. The physical environment includes safety devices, bathroom hazards, materials or objects used in the performance of the activity (e.g., soap, shampoo, towels), and physical space. Physical space comprises the size and layout of the bathroom; doorway width and threshold heights; locations of light switches, outlets, fixtures, appliances; floor material and finishes; light and noise levels; and accessibility and usability of features such as the type of water controls in the tub or shower [14]. The social environment includes support from family or caregivers to perform bathing. Occupation is defined as groups of activities and tasks engaged in to meet personal needs [13]. For the task of bathing, the occupation domain includes bathing routines or method (such as frequency or techniques used) as well as task demands, that is, the specific sub-tasks and actions required to perform the task. The task demands include aspects of sequencing, timing, and required physical and cognitive performance skills [15]. The $P-E-O$ interaction is assessed by the level of ' $f$ it' among the domains of the model [13]. Greater overlap among the domains indicates better fit and, therefore, better bathing performance.

Figure 1. The Person-Environment-Occupation Model for Bathing. Note. The original figure of the P-E-O model appeared in the following article: Fearing V, Law M, Clark J. An occupational performance process model: Fostering client and therapist alliances. Can J Occup Ther 1997;64, p 11. This Figure is reprinted with permission by CAOT Publications.

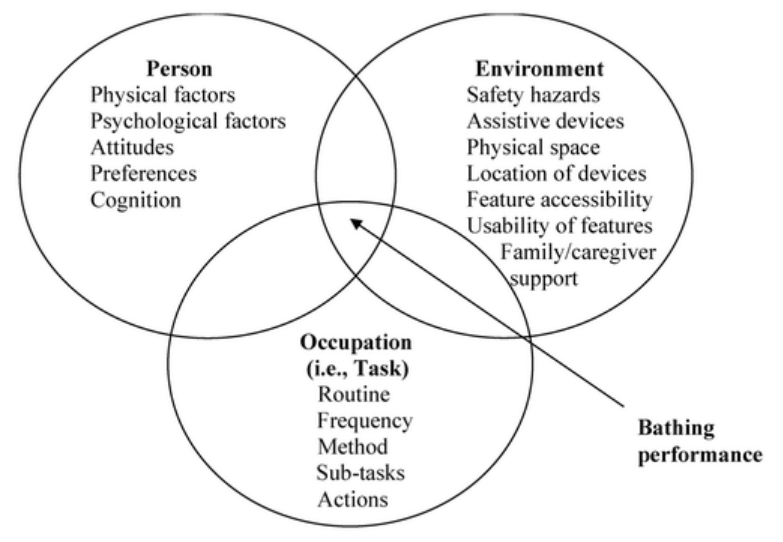

\section{The relationship between person and environment}

Much of the research on bathing has examined the person-environment relationship (that is, the overlap between the person and environment domains of the model in the figure). Most of this research focuses on aspects of the physical environment such as assistive device use and environmental hazards. Population-based studies on assistive device use among community-living older adults carried out in Sweden and in the UK show that bathing devices (e.g., grab bars, raised toilet seat, tub-seat) are most commonly used with a trend of higher usage rates among those who are older [16], female [16-18], and who have visual impairment [17]. The rates and usage of different bathing devices also appear to differ by type and severity of impairments (e.g., cognitive, physical, visual) [19],[20].

Attitudes and preferences about device use have also been examined. Bathing devices have been viewed favourably to promote safety and prevent falls in a study using focus groups [21]. However, problems with using 
bathing devices were common in one study [22]. Reasons for dissatisfaction and disuse of bathing devices included the denial of need, feelings of embarrassment, and awkward or unsafe device use [21],[23],[24].

The bathroom has been cited as one of the most common sites for environmental hazards in the home [25-27]. The relationship between environmental hazards in the home and experiencing falls has been examined in studies [28-32], however, the differences in how environmental hazards are defined make it difficult to synthesize the findings. No studies could be found that focus specifically on the relationship between falls in the bathroom and bathroom environmental hazards. Gill et al. examined the relationship between a specific bathroom hazard, the absence of bathroom grab bars in homes, and physical and psychological factors [33]. For community-living older adults, deficits in standing from a chair and low falls efficacy were associated with having no grab bars in the bathroom which suggests the installation of grab bars is one means to prevent bathing disability.

In summary, research on the relationship between the person and environment focuses on only a few aspects of the physical environment and use of devices. Little is known about the physical environmental features needed for optimal bathing performance (including lighting levels and accessibility of fixtures) or how bathing performance changes with transitions into different environments (such as a move from home to a senior housing facility).

\section{The relationship between person and occupation}

Bathing, as an occupation, has been examined most often through a reduction into bathing sub-tasks. Czaja et al. examined the physical actions required to perform bathing sub-tasks through videotape analysis and found that the most frequent actions were standing, lifting/lowering, and precise finger grips (i.e., to manipulate tub or shower water controls) [34]. Reported bathing difficulty was associated with problems bending and reaching. Naik et al. examined several bathing sub-tasks (such as obtaining and using supplies, getting into bathing position, washing the whole body) and found that difficulty or dependence (i.e., needing personal assistance) was most often reported in the sub-tasks of getting into and leaving the bathing position followed by washing whole body [35]. For the bath transfer alone, studies have found that $12-66 \%$ of community-living older adults report difficulty [23],[35],[36]. The lower prevalence found in one study (12\%) may have been due to the exclusion of participants who required any type of assistance with the bath transfer including stand-by assistance [36].

There is little information on the frequency or routine of bathing among older adults. Aminzadeh et al. found that one-third of residents in senior housing modified their bathing routine due to fear of getting into the tub to bathe [23]. Assessment questions that examine the change in frequency or method of performing everyday tasks have been developed in order to identify signs of 'pre-clinical' disability in community-living older adults [37]. Using an adapted version of these questions for bathing, our research team found that almost half of a sample of 59 older adult residents (47\%) of a congregate housing facility changed their method of bathing due to their health condition, $17 \%$ reduced their frequency of bathing, and $26 \%$ avoided taking tub baths because of difficulty [38].

Studies that have examined the relationship between person and occupation have begun to examine disability in specific bathing subtasks. Little is known about how and when community-living older adults perform bathing to compensate for functional deficits.

\section{The relationship between occupation and environment}

There are few studies that investigate the occupation of bathing as it relates to environmental design. Some biomechanical design studies were undertaken to determine the physical space requirements needed for bath and shower transfers for wheelchair users [39],[40], to determine specifications for bathroom grab bars [41], 
and to test specific tub and shower seats among older adults and spinal cord injured patients [42]. These studies provide important preliminary information about bathroom design; however, most of them lack a standard protocol and detail about how the studies were conducted which make them difficult to synthesize [43].

Another approach used to enhance bathroom design in assisted living and dementia-specific facilities is postoccupancy evaluation. Specifically, architects design or redesign buildings based on information about how people perform within the environment which often involves interviewing staff members and facility residents [44],[45]. Post-occupancy evaluations vary widely in the amount of time to conduct and number of people involved. In one study, an environmental researcher was trained as a nursing assistant and worked at a dementia-specific facility for several weeks in order to identify problems and help redesign facility bathrooms to better ensure safety, reduce fear of bathing, and provide ease of cleaning [44].

Based on these studies, more work is needed to examine physical factors of bathrooms for frail older adults as well as those with specific disabilities. These studies should include a broad set of physical environmental features.

\section{The person-environment-occupation interaction}

Community-living older adults

Whereas most bathing studies have examined pieces of the P-E-O interaction, few studies have comprehensively assessed bathing disability by examining all domains (P-E-O) involved in bathing performance. Studies that assessed the $\mathrm{P}-\mathrm{E}-\mathrm{O}$ interaction in bathing have examined how the physical environment is utilized during a bath transfer [23],[36],[46] and performance difficulties experienced [36]. In the studies of environmental utilization, grab bars are the most commonly utilized feature during the bath transfer; however, high rates of utilization of unsafe environmental features (i.e. ones not designed to be used as a support such as the bathtub perimeter or sink tops) have been reported [23] and observed [36]. Utilization of bathroom environmental features (i.e., nonskid mats, grab bars, shower chair, handheld shower, long handled sponge, or emergency rescue device) was found to be higher among independently-bathing older adults with observed deficits standing from a chair compared to those with no observed deficits [46]. In addition, increased utilization of bathroom environmental features is independently associated with self-reported difficulty with the bath transfer [36]. In the only study found that examined performance difficulties (defined as lack of fluid movement or difficulty negotiating the environment) [36], one-third of older adults who reported independence in bathing had one or more observed performance difficulties. Of the performance difficulties measured, falling or 'plopping' onto a tub seat or into the tub was the most common (51\%).

Older adults with dementia

Two studies have been found to have assessed the P-E-O interaction for older adults with dementia. They examine both the physical environment and social environment (i.e., the caregiver-client relationship). These studies describe the specific problems with the P-E-O interaction experienced by caregivers and older adults to create intervention strategies [47],[48]. Bathing problems as reported by caregivers included resistance in performing bathing, agitation, lack of ability to follow the bathing routine, and safety [48].

The few studies on bathing among older adults with dementia consider many aspects of the P-E-O interaction. Studies on the P-E-O interaction in community-living older adults are currently limited to how adults function within the physical bathroom environment. More work is needed to examine how bathing is performed or how it changes over time considering social support factors (such as help from a spouse).

\section{Recommendations to improve bathing performance based on the literature}

- The use of assistive devices is commonly recommended, however, adequate training and follow-up with use of devices prescribed by therapists is needed to promote device use [24]. 
- Since the bath transfer is the most problematic bathing sub-task [35] and performance difficulties during the bath transfer are only independently associated with having functional limitations in range of motion and low falls efficacy [36], environmental solutions and practicing bathing strategy may be more appropriate methods of reducing performance difficulties when compared to remediation of personal capacities.

- The high rate of unsafe environmental feature utilization, even in housing facilities designed for older adults [23],[36], indicates the need for intervention for community-living older adults to help prevent bathroom-related falls and bathing disability.

\section{Bathing interventions}

\section{Community-living older adults}

Few studies have evaluated the effectiveness of bathing interventions. Table I shows intervention studies that include bathing treatment or focus only on bathing in community-living older adults and in older adults with dementia. For community-living older adults, bathing has been included in the context of broader interventions designed to modify the home environment and to prescribe and teach the use of assistive devices [49-51]. Bathing was also included in a multi-factorial fall prevention intervention in which assistive devices and exercise were possible treatments for unsafe bath transfers [52]. Only two studies could be found that tested specific bathing interventions [53],[54]. One study examined the effect of home training in bathing device use among stroke patients recently discharged from the hospital in a randomized control trial $(n=53)$ [53]. The intervention group (who received $1-3$ home visits) had significantly higher physical function, reported satisfaction with the devices, and a higher rate of device use than the control group at 3 months follow-up. The other bathing study was done to examine the effectiveness of a housing advocacy program that provides bathroom devices to lowincome frail older adult renters [54]. Among the small sample who were seen at baseline and follow-up $(n=20)$, older adults who received the bathing intervention (i.e., two home visits from an occupational therapist involving identification of assistive device needs and prescription of devices) had significant improvement in the ability to bathe after the intervention. Given the current lack of research in this area, studies that examine bathing interventions geared to community-living older adults are needed.

Table I. Interventions that include or focus on bathing in older adults.

\begin{tabular}{|c|c|c|c|c|}
\hline $\begin{array}{c}\text { Author(s), } \\
\text { year }\end{array}$ & Sample & $\begin{array}{l}\text { Study } \\
\text { design }\end{array}$ & Intervention & Results \\
\hline \multicolumn{5}{|l|}{$\begin{array}{l}\text { Community- } \\
\text { living older } \\
\text { adults }\end{array}$} \\
\hline $\begin{array}{l}\text { Cumming et } \\
\text { al. } 1999 \text { [49] }\end{array}$ & $\begin{array}{l}530 \text { older adults recently } \\
\text { discharged from hospital, mean } \\
\text { age } 77 \text { years }\end{array}$ & RCT & $\begin{array}{l}\text { A home visit by an occupational therapist for } \\
\text { environmental hazard reduction and home } \\
\text { modification }\end{array}$ & $\begin{array}{l}\text { Among prior fallers, reduced rate of falls in } \\
\text { the intervention group compared to } \\
\text { control group. }\end{array}$ \\
\hline $\begin{array}{l}\text { Mann et al. } \\
1999[50]\end{array}$ & $\begin{array}{l}104 \text { frail older adults, mean age } \\
73 \text { years }\end{array}$ & RCT & $\begin{array}{l}\text { Provision of assistive devices and home } \\
\text { modification over } 18 \text { month period }\end{array}$ & $\begin{array}{l}\text { Both treatment and control group declined } \\
\text { on overall functional status (on FIM), but } \\
\text { treatment group had significantly less } \\
\text { decline. }\end{array}$ \\
\hline $\begin{array}{c}\text { Stark } \\
2004[51]\end{array}$ & $\begin{array}{l}16 \text { low income older adults } \\
\text { with activities of daily living } \\
\text { impairment, mean age } 67 \text { years }\end{array}$ & $\begin{array}{l}\text { Pretest- } \\
\text { Posttest }\end{array}$ & $\begin{array}{l}\text { Provision of adaptive equipment and home } \\
\text { modification (baseline, 3-month, and 6-month } \\
\text { follow-up visits) }\end{array}$ & $\begin{array}{l}\text { At post-test, participants had significantly } \\
\text { higher scores on satisfaction and } \\
\text { performance subscales of the Canadian } \\
\text { Occupational Performance Measure } \\
\text { (COPM). }\end{array}$ \\
\hline $\begin{array}{l}\text { Tinetti et al. } \\
1994[52]\end{array}$ & $\begin{array}{l}301 \text { community-living older } \\
\text { adults with at least one fall risk } \\
\text { factor (including the inability to } \\
\text { transfer to bath/toilet safely), } \\
\text { mean age } 70 \text { years }\end{array}$ & RCT & $\begin{array}{l}\text { Based on baseline individual risk factors, } \\
\text { participants in the intervention group received } \\
2-22 \text { visits of exercise, transfer skills training, } \\
\text { or environmental modification. Control group } \\
\text { participants received equivalent social contact } \\
\text { visits }\end{array}$ & $\begin{array}{l}\text { Of all participants who had unsafe } \\
\text { bath/toilet transfers at baseline, } \\
\text { significantly more of the control group } \\
\text { continued to have unsafe transfers at post- } \\
\text { test compared to the intervention group } \\
(65 \% \text { vs. } 49 \%, p=0.05) \text {. }\end{array}$ \\
\hline $\begin{array}{l}\text { Chiu et al. } \\
2004[53]\end{array}$ & $\begin{array}{l}53 \text { older adults who had } \\
\text { experienced a stroke in need of } \\
\text { bathing devices who were }\end{array}$ & RCT & $\begin{array}{l}\text { Intervention and control groups received } \\
\text { assistive device training in the hospital and one } \\
\text { home visit pre-discharge, intervention group } \\
\text { received } 2-3 \text { home visits for additional }\end{array}$ & $\begin{array}{l}\text { Participants in the intervention group had } \\
\text { significantly higher functioning (on FIM) } \\
\text { and satisfaction with devices. Bathing } \\
\text { devices were more utilized in the }\end{array}$ \\
\hline
\end{tabular}




\begin{tabular}{|c|c|c|c|c|}
\hline & $\begin{array}{l}\text { about to be discharged from } \\
\text { the hospital, mean age } 72 \text { years }\end{array}$ & & $\begin{array}{l}\text { instruction on assistive device use and safety } \\
\text { techniques }\end{array}$ & $\begin{array}{l}\text { intervention group compared to controls } \\
(97 \% \text { vs. } 57 \%) \text {. }\end{array}$ \\
\hline $\begin{array}{l}\text { Gitlin et al. } \\
1999[54]\end{array}$ & 34 low income older adults & $\begin{array}{l}\text { Pretest- } \\
\text { Posttest }\end{array}$ & $\begin{array}{l}\text { Two home visits by an occupational therapist } \\
\text { for assessment of self-care and provision of } \\
\text { assistive devices }\end{array}$ & $\begin{array}{l}\text { Significant improvement in bathing ability } \\
\text { (assessed on a difficulty scale by OT) at } \\
\text { post-test. }\end{array}$ \\
\hline \multicolumn{5}{|l|}{$\begin{array}{l}\text { Older adults } \\
\text { with dementia }\end{array}$} \\
\hline $\begin{array}{l}\text { Gitlin et al. } \\
2001[55]\end{array}$ & $\begin{array}{l}171 \text { family caregivers of older } \\
\text { adults with dementia }\end{array}$ & RCT & $\begin{array}{l}\text { Five 90-min home visits with caregivers by } \\
\text { occupational therapist for education and } \\
\text { physical and social environment modification }\end{array}$ & $\begin{array}{l}\text { Intervention caregivers reported less } \\
\text { declines in self-care and behaviour } \\
\text { problems at } 3 \text { months. Women caregivers } \\
\text { reported increased self-efficacy in handling } \\
\text { behaviours and dependency. }\end{array}$ \\
\hline $\begin{array}{l}\text { Gitlin et al. } \\
2003[56]\end{array}$ & $\begin{array}{l}255 \text { family caregivers of older } \\
\text { adults with dementia }\end{array}$ & RCT & Five home visits and one telephone contact & $\begin{array}{l}\text { Intervention caregivers reported less upset } \\
\text { with behaviour problems, less need for } \\
\text { assistance from others, and better affect. }\end{array}$ \\
\hline $\begin{array}{l}\text { Sloane et al. } \\
2004 \text { [58] }\end{array}$ & $\begin{array}{l}73 \text { nursing home residents with } \\
\text { dementia and agitation during } \\
\text { bathing; } 73 \text { nursing assistants }\end{array}$ & $\mathrm{RCT}$ & $\begin{array}{l}\text { Participants received baths which were } \\
\text { person-centred, towel baths, or usual bath } \\
\text { method from nursing assistants }\end{array}$ & $\begin{array}{l}\text { Aggression declined most with person- } \\
\text { centred bathing, followed by towel baths, } \\
\text { discomfort declined significantly in both } \\
\text { intervention and control groups. }\end{array}$ \\
\hline
\end{tabular}

\section{Older adults with dementia}

A few studies focused on manipulating the environment and training caregivers of older adults with dementia to enable better performance in daily living tasks which included bathing [55],[56]. These studies used a multilayered theoretical model in which the environment was divided into object, task, social group, and culture [57]. In one study that particularly focused on the bathing task, several strategies were devised to enhance the P-E-O interaction such as removing unnecessary objects (object level), use of verbal and tactile cueing (task), use of a formal healthcare provider (social group), and positive reinforcement of appropriate behaviours (culture) [48]. In a randomized controlled trial, Sloane et al. tested the effectiveness of two types of bathing approaches (person-focused showering and towel bed bath) in which members of staff were trained to work with older adults with dementia who reside in nursing homes [58]. Both approaches led to significantly fewer incidents of agitation and aggression and less discomfort experienced by residents.

Most of the intervention studies found do not focus solely on bathing. Only three studies have specifically designed interventions that focus on bathing [53],[54],[58], and of those studies, only one examined the P-E-O interaction in bathing rigorously [58]. In these studies, intervention outcomes vary widely.

\section{Future directions for bathing disability research using the P-E-O model}

Based on this review, different groups of older adults are being targeted for bathing interventions based on their functional status: Community-living well older adults, older adults who have experienced a significant health event such as a stroke, and older adults who have dementia. Bathing disability has been assessed in a variety of ways and based on other studies in this review, there is a potential to assess many other aspects of the P-E-O interaction in bathing.Table II, which is offered as a framework to guide research development for future intervention studies, shows the different groups of older adults, intervention goals based on expectation of functional improvement, and assessment of the P-E-O interaction for tracking outcomes or guiding intervention strategies.

Table II. Application of the P-E-O interaction for bathing intervention.

\begin{tabular}{|c|c|c|}
\hline Older adults by functional status & Intervention goals & Assessment of the P-E-O interaction* \\
\hline \multirow[t]{2}{*}{ Independent or independent with difficulty } & - Help prevent future disability & - Presence of environmental hazards \\
\hline & - $\quad$ Reduce difficulty in bathing & - Utilization of environmental features \\
\hline \multicolumn{3}{|l|}{ - Performance difficulties } \\
\hline \multirow[t]{2}{*}{ Requires assistance - expect improvement in functional status } & - Increase independence in bathing & - Measurement of bathing performance \\
\hline & - Increase safety in bathing & $\wedge$ Stand-by assistance \\
\hline$\wedge^{\prime}$ Environmental set-up & & \\
\hline Verbal and physical cueing & & \\
\hline$\wedge$ Minimal physical assistance & & \\
\hline Moderate physical assistance & & \\
\hline
\end{tabular}




\begin{tabular}{|l|l|l|}
\hline \multicolumn{1}{|c|}{ Maximal physical assistance } & & \\
\hline $\begin{array}{l}\text { Requires assistance }- \text { expect no improvement in functional } \\
\text { status }\end{array}$ & $\begin{array}{l}\bullet \text { Improve client-caregiver } \\
\text { interaction }\end{array}$ & $\bullet$ Caregiver difficulty \\
\hline & $\bullet$ Increase quality of bathing & $\begin{array}{l}\bullet \text { Client behaviours }- \text { Agitation, aggression, } \\
\text { discomfort }\end{array}$ \\
\hline$\bullet \quad$ Cleanliness, skin condition & & \\
\hline
\end{tabular}

*The P-E-O interaction is assessed to track outcomes or to guide intervention strategies.

For well older adults who report being independent in bathing or who report that they are independent but have some difficulty bathing, intervention goals and aspects of the P-E-O interaction have not yet been welldelineated or examined in research studies. Ways to assess the P-E-O interaction include examination of the presence of environmental hazards, utilization of many environmental features, and observed performance difficulties.

For older adults who require assistance but have the potential to improve their functional status, assessment of the P-E-O interaction includes a functional measure of bathing performance. Most of what is known about bathing disability comes from self-report measures, such as the modified version of the Katz ADL index (which assesses dependence in bathing by the reported need for any personal assistance or equipment help) [59]. Some studies that assess bathing disability with self-report measures have also added a question about difficulty performing bathing [35],[44]. Although assessment of difficulty provides more information about people at earlier stages of disability, additional specification is needed to include assessment of those who need or prefer stand-by assistance to bathe.

Although self-report disability measures are easy to administer, studies have found that they are not strongly related to performance-based measures [60],[61] and they are not as sensitive to early decline [62]. Therefore, the use of performance-based bathing assessments would strengthen studies. Several performance-based activities of daily living assessments exist within the field of rehabilitation [63-66]. The Functional Independence Measure (FIM), part of the Uniform Data System for Medical Rehabilitation, is one of the most widely-accepted measures used to track progress of rehabilitation clients [59]. Although two intervention studies in this review used the FIM as an outcome measure [50],[53], the bathing item was subsumed in an entire score on a 'motor' subscale and thus it is impossible to know how much bathing itself has changed or which sub-tasks were improved.

The Performance Assessment of Self-Care Skills (PASS) [66] may be a particularly good tool to examine bathing disability. This criterion-referenced assessment has established reliability (test-retest and inter-rater) and validity (content and construct) [67] and measures the amount of physical and cognitive assistance needed to perform bathing sub-tasks as well as safety and adequacy of performance. Bathing performance is graded according to a hierarchy of assistance: verbal cueing (supportive, non-directive, directive), gestures, environmental set-up, demonstration, physical guidance, physical support, and total assistance. Performancebased measures are important to incorporate in bathing studies in order to better quantify the P-E-O interaction in bathing and to more precisely measure the effectiveness of bathing interventions.

For older adults with dementia (who require assistance and whose function is not expected to improve), research studies have assessed the P-E-O interaction by examining caregiver burden and problems that cannot be articulated by clients themselves (i.e., behaviours) [48],[58]. In addition, goals were identified for bathing interventions that include improving the client-caregiver interaction and increasing the quality of bathing.

\section{Conclusions}

There is a dearth of bathing research on community-living older adults and high quality bathing intervention studies are needed. Using the P-E-O model to examine bathing disability research has revealed many areas of 
bathing disability that have been unexplored in the research. Improvements in the assessment of P-E-O interaction in bathing will help to better track bathing outcomes and help to guide remediation and prevention efforts.

\section{Acknowledgements}

The work from this study was supported in part by grants from the Department of Veteran Affairs Research and Development, the National Institute on Aging (NIA) Claude Pepper Older Adults Independence Center (AG08808) as well as NIA grant AG10542. Dr Murphy is a recipient of a K01 Mentored Research Scientist Development Award from the National Center for Medical Rehabilitation Research (K01 HD045293) and Dr Alexander is a recipient of a K24 Mid-Career Investigator Award in Patient-Oriented Research AG109675 from NIA. We thank Elizabeth Walker-Peterson, MPH, OTR \& Susan H. Lin, SCD, OTR/L for earlier reviews of this manuscript.

\section{References}

1. Wiener J M, Hanley R J, Clark R, Van Nostrand J F. Measuring the activities of daily living: Comparisons across national surveys. J Gerontol: Soc Sci 1990, 45: S229-S237

2. Dunlop D D, Hughes S L, Manheim L M. Disability in activities of daily living: Patterns of change and a hierarchy of disability. Am J Pub Health 1997; 87: 378-383

3. Jagger C, Arthur A J, Spiers N A, et al. Patterns of onset of disability in activities of daily living with age. J Am Geriatr Soc 2001; 49: 404-409

4. Reuben D B, Keeler E, Seeman $T$, et al. Development of a method to identify seniors at high risk for high hospital utilization. Med Care 2002; 40: 782-793

5. Brody K K, Johnson R E, Douglas R L. Evaluation of a self-report screening instrument to predict frailty outcomes in aging populations. Gerontologist 1997; 37: 182-191

6. Ostbye T, Walton R E, Steenhuis R, Hodsman A B. Predictors and sequelae of fractures in the elderly: The Canadian study of health and aging. Can J Aging 2004; 23: 247-253

7. Carey E C, Walter L C, Lindquist K, Covinsky K E. Development and validation of a functional morbidity index to predict mortality in community-dwelling elders. J Gen Intern Med 2004; 19: 1027-1033

8. Satarino W A. The disabilities of aging - looking to the physical environment [editorial]. Am J Pub Health 1997; 87: 331-332

9. Verbrugge $L M$, Jette A M. The disablement process. Soc Sci Med 1994; 38: 1-14

10. Gitlin L N. Conducting research on home environments: Lessons learned and new directions. Gerontologist 2003; 43: 628-637

11. Iwarsson S. Assessing the fit between older people and their physical home environments: An occupational therapy research perspective. Annual review of gerontology and geriatrics, 23. Aging in context: Socio-physical environments, H W Wahl, R J Scheidt, P G Windley. Springer, New York 2003

12. Stucki G. International Classification of Functioning, Disability, and Health (ICF): A promising framework and classification for rehabilitation medicine. Am J Phys Med Rehabil 2005; 84: 733-740

13. Law M, Cooper B, Strong S, et al. The person-environment-occupation model: A transactive approach to occupational therapy. Can J Occup Ther 1996; 63: 9-23

14. Connell B R, Sanford J A. Individualizing home modification. Recommendations to facilitate performance of routine activities. Staying put: Adapting the places instead of the people, S Lanspery, J Hyde. Baywood, New York 1997; 113-147

15. American Occupational Therapy Association. Occupational therapy practice framework: Domain and process. Am J Occup Ther 2002; 56: 609-639

16. Sonn U, Grimby G. Assistive devices in an elderly population studied at 70 and 76 years of age. Disabil Rehabil 1994; 16: 85-92 
17. Dahlin-Ivanhoff S, Sonn U. Use of assistive devices in daily activities among 85-year-olds living at home focusing especially on the visually impaired. Disabil Rehabil 2004; 24: 1423-1430

18. Edwards $\mathrm{N} \mathrm{I}$, Jones D A. Ownership and use of assistive devices amongst older people in the community. Age Ageing 1998; 27: 463-468

19. Mann W C, Hurren D, Tomita M. Comparison of assistive device use and needs of home-based older persons with different impairments. Am J Occup Ther 1993; 47: 980-987

20. Mann W C, Hurren D, Tomita M. Assistive devices used by home-based elderly persons with arthritis. Am J Occup Ther 1995; 49: 810-820

21. Aminzadeh F, Edwards N. Exploring seniors' views on the use of assistive devices in fall prevention. Public Health Nurs 1998; 15: 297-304

22. Mann W C, Hurren D, Tomita M, et al. Use of assistive devices for bathing by elderly who are not institutionalized. Occup Ther J Res 1996; 16: 261-287

23. Aminzadeh $F$, Edwards $N$, Lockett $D$, et al. Utilization of bathroom safety devices, patterns of bathing and toileting, and bathroom falls in a sample of community living older adults. Technol Disabil 2000; 13: 95-103

24. Wielandt $T$, McKenna $K$, Tooth $L$, et al. Post discharge use of bathing equipment prescribed by occupational therapists: What lessons can be learned?. Phys Occup Ther Geriatr 2001; 19: 47-63

25. Carter S E, Campbell E M, Sanson-Fisher R W, et al. Environmental hazards in the homes of older people. Age Ageing 1997; 26: 195-202

26. Clemson L, Roland M, Cumming R G. Types of hazards in the homes of elderly people. Occup Ther J Res 1997; 17: 200-213

27. Gill T M, Williams C S, Robison J T, et al. A population-based study of environmental hazards in the homes of older persons. Am J Pub Health 1999; 89: 553-556

28. Connell B R. Role of the environment in falls prevention. Clin Geriatric Med 1996; 12: 859-880

29. Gill T M, Williams C S, Tinetti M E. Environmental hazards and the risk of nonsyncopal falls in the homes of community-living older persons. Med Care 2000; 38: 1174-1183

30. Sattin R W, Rodriguez J G, DeVito CA, et al. Home environmental hazards and the risk of fall injury events among community-dwelling older persons. Study to assess falls among the elderly (SAFE) group. J Am Geriatr Soc 1998; 46: 669-676

31. Tinetti M E, Doucette J T, Claus E B. The contribution of predisposing and situational risk factors to serious fall injuries. J Am Geriatr Soc 1995; 43: 1207-1213

32. van Bemmel T, Vandenbroucke J P, Westendorp R GJ, et al. In an observational study elderly patients had an increased risk of falling due to home hazards. J Clin Epidemiol 2005; 58: 63-67

33. Gill T M, Robison J T, Williams C S, et al. Mismatches between the home environment and physical capabilities among community-living older persons. J Am Geriatr Soc 1999; 47: 88-92

34. Cjaza S J, Weber R A, Nair S N. A human factors analysis of ADL activities: A capability-demand approach. J Gerontol 1993; 48(special issue)44-48

35. Naik A D, Concato J, Gill T M. Bathing disability in community-living older persons: Common, consequential, and complex. J Am Geriatr Soc 2004; 52: 1805-1810

36. Murphy S L, Nyquist L V, Strasburg D, et al. Bath transfers among older adult congregate housing residents: Assessing the person-environment interaction. J Am Geriatr Soc 2006; 54: 1265-1270

37. Fried L P, Bandeen-Roche K, Williamson J D, et al. Functional decline in older adults: Expanding methods of ascertainment. J Gerontol Med Sci 1996; 51A: M206-M214

38. Nyquist L V, Alexander N B, Gee K, Bade S, Gell N. Using self-report to demarcate phases of a continuum of disability: Difficulty and task modification [abstract]. Gerontologist 1999; 39: 156 
39. Ownsworth A, Galer M, Feeney R J. Housing for the disabled. Part 2. An ergonomic study of the space requirements of wheelchair users for bathrooms. University of Technology, Institute of Consumer Ergonomics, LoughboroughUK 1974

40. Steinfeld E, Schroeder S, Bishop M. Accessible buildings for people with walking and reaching limitations. Department of Housing and Urban Development, Washington, DC 1979

41. McLelland I. Bath aids for the disabled. University of Technology, Institute for Consumer Ergonomics, Loughborough, UK 1972

42. Malassigne $P$, Sanford J, Cors $M$, et al. From the drawing board: New bathing and toileting designs provide ease of access to older adults and individuals with disabilities. Rehab Manage 2003; 16(34)3641

43. van der Voordt T JM. Space requirements for accessibility: Cross-cultural comparisons. Enabling environments: Measuring the impact of the environment on disability and rehabilitation, E Steinfeld, G S Danford. Plenum, New York 1999; 59-88

44. Norieka J, Kujoth J, Torgrude S. Using post-occupancy evaluation to guide bathroom design in a dementia-specific assisted-living facility. Alzheimer's Care Quart 2002; 3: 32-37

45. Cooper B A, Ahrentzen S, Hasselkus B. Post-occupancy evaluation: An environment-behavior technique for assessing the built environment. Canadian J of Occup Ther 1991; 58: 181-188

46. Naik A D, Gill T M. Underutilization of environmental adaptations for bathing in community-living older adults. J Am Geriatr Soc 2005; 53: 1497-1503

47. Corcoran M, Gitlin L N. Environmental influences on behavior of the elderly with dementia: Principles for intervention in the home. Phys Occup Ther Geriatr 1991; 9: 5-22

48. Gitlin L N, Corcoran M. Expanding caregiver ability to use environmental solutions for problems of bathing and incontinence in the elderly with dementia. Technol Disabil 1993; 2 : 12-21

49. Cumming R G, Thomas M, Szonyi G, et al. Home visits by an occupational therapist for assessment and modification of environmental hazards: A randomized trial of falls prevention. J Am Geriatr Soc 1999; 47: 1397-1402

50. Mann W C, Ottenbacher K J, Fraas L, et al. Effectiveness of assistive technology and environmental interventions in maintaining independence and reducing home care costs for the frail elderly: $\mathrm{A}$ randomized controlled trial. Arch Fam Med 1999; 8: 210-217

51. Stark S. Removing environmental barriers in the homes of older adults with disabilities improves occupational performance. Occup Ther J Res 2004; 24: 32-39

52. Tinetti $M E$, Baker $D \mathrm{I}, \mathrm{McAvay} \mathrm{G}$, et al. A multifactorial intervention to reduce the risk of falling among elderly people living in the community. N Engl J Med 1994; 331: 821-827

53. Chiu C WY, Man D WK. The effect of training older adults with stroke to use home-based assistive devices. Occup Ther J Res 2004; 24: 113-120

54. Gitlin L N, Miller K S, Boyce A. Bathroom modifications for frail elderly renters: Outcomes of a community-based program. Technol Disabil 1999; 10: 141-149

55. Gitlin L N, Corcoran M, Winter L. A randomized, controlled trial of a home environmental intervention: Effect on efficacy and upset in caregivers and on daily function of persons with dementia. Gerontologist 2001; 1: 4-14

56. Gitlin L N, Winter L, Corcoran M A, et al. Effects of a home environmental skill-building program on the caregiver-care recipient dyad: 6-month outcomes from the Philadelphia REACH initiative. Gerontologist 2003; 43: 532-546

57. Barris $R$, Kielhofner $G$, Levine $R E$, . Occupation as interaction with the environment. A model of human occupation: theory and application, G Kielhofner, et al. Williams and Wilkins, Baltimore, MD 1985; 4262 
58. Sloane P D, Hoeffer B, Mitchell C M, et al. Effect of person-centered showering and the towel bath on bathing-associated aggression, agitation, and discomfort in nursing home residents with dementia: $\mathrm{A}$ randomized controlled trial. J Am Geriatr Soc 2004; 52: 1795-1804

59. Branch L G, Katz S, Kniepmann K, Papsidero J A. A prospective study of functional status among community elders. Am J Pub Health 1984; 74: 266-268

60. Wittink H, Rogers W, Sukiennik A, Carr D B. Physical functioning: Self-report and performance measures are related but distinct. Spine 2003; 28: 2407-2413

61. Rogers J, Holm M B, Beach S, et al. Concordance of four methods of disability assessment using performance in the home as the criterion method. Arth Rheum 2003; 49: 640-647

62. Brach J S, VanSwearingen J M, Newman A B, Kriska A M. Identifying early decline of physical function in community-dwelling older women: Performance-based and self-report measures. Phys Ther 2002; 82: $320-328$

63. Linacre J M, Heinemann A W, Wright B D, et al. The structure and stability of the functional independence measure. Arch Phys Med Rehabil 1994; 75: 127-132

64. Klein R M, Bell B J. Klein-Bell Activities of Daily Living Scale. University of Washington, Seattle, WA 1979

65. Mahoney S I, Barthel D W. Functional evaluation: The Barthel Index. Maryland State Med J 1965; 14: 6165

66. Rogers J, Holm M. Performance assessment of self-care skills. University of Pittsburgh, Pittsburgh, PA 1989

67. Holm M B, Rogers J C. Performance assessment of self-care skills. Assessments in occupational therapy mental health: An integrative approach, B Hemphill-Pearson. Slack, Thorofare, NJ 1999; 117-124 